\title{
Article \\ Mechanical and Microstructural Characteristics of the Fiber-Reinforced Composite Materials
}

\author{
Zhang Wei ${ }^{1,2}$ \\ 1 Mining \& Mineral Resources Division, Department of Business Administration, \\ Chinalco China Copper Corporation Limited, Beijing 100082, China; zhang_wei@chalco.com.cn \\ 2 Department of Mining and Materials Engineering, McGill University, Montreal, QC H3A 0C5, Canada
}

\begin{abstract}
Composite fiber materials are superior materials due to their high strength and light weight. Composites reflect the properties of their constituents, which is proportional to the volume fraction of each phase. There are different fiber reinforcement types and each affects it's flexural, tensile and compression strength. When selecting a composite for a specific application, the forces excreted on the composite must be known in order to determine the reinforcement type. Unidirectional fiber reinforcement will allow very strong load resistance but only in one direction where as a random orientated fiber reinforcement can resist less load but can maintain this quota in all directions. These materials are said to be anisotropic. Certain composite fibers, taking into consideration there weights, are physically stronger than conventional metals. This research deals with the analysis of three composite materials with different reinforcement types, volume fraction and phase content. It was found that material A (glass epoxy) was the strongest in the longitudinal direction with a flexural strength of $534 \mathrm{MPa}$ in the longitudinal and 420 $\mathrm{MPa}$ in the transverse direction. The flexural stresses of material B (glass silicone) and material $\mathrm{C}$ (glass polyester) where both found in the 120 to $135 \mathrm{MPa}$ range. Differences were due to their differences in matrix composition and reinforcement type.
\end{abstract}

Keywords: composite fibers; flexural strength; polyester matrix; reinforcement

\section{Introduction}

In modern times, materials consisting of different properties are much needed for different applications [1-3]. These special properties are not found with the conventional materials such as pure metals, ceramics and polymers. Aerospace engineers are consistently in search and demand a material that has outstanding strength, low density and increased structural stiffness [4]. These materials are the sum of combination of characteristics and only possible through composite materials. A composite is best defined as a material considered containing two or more multiphase materials that exhibits a significant portion of the properties of all the constituent phase. These combinations of properties are engineered to improve performance according to the specific application [5-6]. The properties of the composite are dependent of the mechanical properties of the constituent phases, the bond strength at the interfaces of the phases, the orientation and volume fraction of the phases.

Composites have been used for many decades [1, 6-7]. Metal alloys are considered composite because they contain multiphase chemical compositions. One example of such alloy is pearlitic steels. This alloy has a microstructure that contains alternating layers of ferrite and cementite. The ferrite phase is soft and ductile while the cementite phase is hard and brittle. The end product of pearlitic steels is a ductile material is much improved strength. Much superior 
mechanical properties than any of the two phase on there own. The strength and ductility depends on the volume fraction of each phase along with other factor described above. Metals tend to behave much more isotropic due to perfectly symmetrical phases in all directions produced by bond forming and grain growth distribution upon cooling or quenching. Polymer fiber composite are anisotropic [8-9]. The composite experiences different mechanical properties in different directions [9]. This is the case because the orientation of the fibers is not symmetrical. Polymers with a fine particle phase and random orientation tend to behave more isotropic.

The objective of this research is to characterize different polymer composite by analyzing optical and SEM images. By characterizing the orientation and volume fraction of these composite polymers, the failure mechanisms of these composite would be understood. Isotropic characterization will also be possible to identify of each sample from observing the optical and SEM images and by analyzing the failure point on the force vs. displacement graph.

\section{Materials}

The role of the fibers in the matrix is to strengthen the material to reduce deformation [10]. The fibers usually consist of glass or carbon molecules. Excellent materials used to increase the strength, stiffness and the toughness of the material. The disadvantage is making the material more vulnerable to fatigue and creep. The matrix phase protects the fibers from damaging. They essentially transfer stresses to the load bearing fibers as well as transmitting shear loads between the layers of fibers. The matrix phase retain order in the fibers and reduce the tendency to transmit stresses from broken fibers to intact ones.

Carbon fiber reinforcement plastic (CFRP) are composites which are very strong, light and expensive [11]. The labor involved in producing these materials in specific shapes is what makes these materials so expensive. The plastic matrix usually is made from an epoxy. Other matrix materials such as polyester, vinyl ester and nylon are also used. These materials are very popular in the aerospace and automotive industry. Also consistently used constructing sailboats. The fact that these composites are so light and strong, they are excellent candidates for manufacturing formula 1 racing components. Glass fiber reinforcement plastics (GFRP) contain fine fibers of glass in there epoxy matrix. Other materials such as polyester and vinylester are used for it's matrix phase. The matrix are very strong resistances against compression forces while the glass fibers resist tensile forces very well. Together the composite has the best of both worlds in resisting against tensile and compression forces. Mostly used in telecommunications, constructing antennas and used on aircrafts.

The arrangement and orientation of the fibers has a great affect on the mechanical properties of the composite [3]. Focusing on orientation alone, two foremost scenarios are possible. The first case, being a parallel alignment of the longitudinal axis of the fibers in a single direction. The second case, a complete random alignment of fibers within the matrix. One single alignment axis makes the material anisotropic. The material is significantly stronger in one direction rather than another. Random fiber orientation holds an isotropic material where the mechanical properties are constant in all directions of the material. A higher load may be obtained for an anisotropic material if the force is applied to the correct direction of the composite. Other parameters that affect the properties of the matrix are the properties of the constituents used for the matrix and the fiber, the volume fraction, the bond strength at the fiber-matrix interface and density distribution.

The stress-strain behavior of brittle materials is not usually obtained from a tensile test [12]. It is somewhat difficult to produce a test specimen with the required dimensions. The results may also vary due to the gripping imperfections of brittle materials onto the tensile apparatus. The 
brittle specimen may fracture with little strain experienced, involving bending stresses that will corrupt the data results. To avoid these imperfections, the flexural test is used. It consists of a rod specimen with a circular or rectangular cross-section that is placed onto a three-point or fourpoint loading apparatus. A three-point apparatus is displayed below in fig 1 .

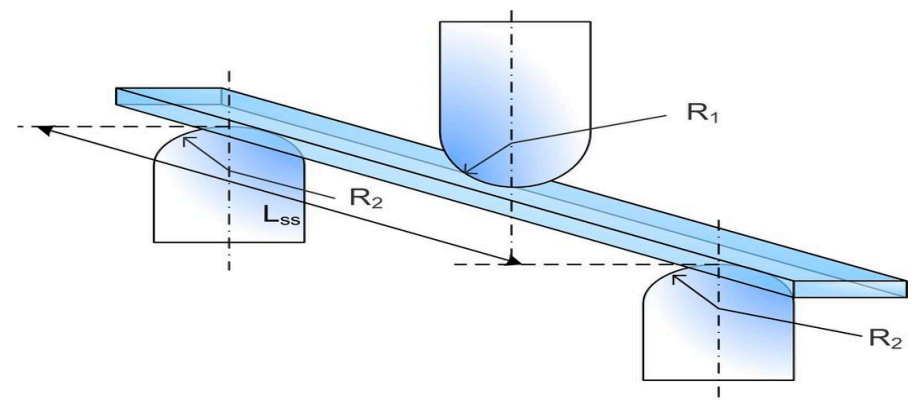

Figure 1. A three-point loading scheme for measuring the stress-strain behavior and flexural strength of brittle materials [1]

At the point of loading, the top surface of the specimen is exposed to compression while the bottom surface experiences tension. The specimen is exposed to an increase in force applied until failure. Stress is computed from the specimen thickness, bending moment and the moment of inertia of the cross section. The maximum tensile force is located directly under the point of load application. Since brittle materials resist compression forces approximately 10 times more than tension forces, the material will fail on the tensile face. For rectangular cross-section specimens, the flexural stress, flexural strain and elastic modulus is expressed as follows:

$$
\begin{gathered}
\sigma_{f}=\frac{3 F L}{2 b d^{2}} \\
\varepsilon_{f}=\frac{6 D d}{L^{2}} \\
E=\frac{F L^{3} m}{4 b d^{3}}
\end{gathered}
$$

From Eq.1, the variable $\mathrm{F}$ is the force applied to the specimen, $\mathrm{L}$ is the support span, $\mathrm{b}$ is defined as the width of the test beam and $d$ is the depth of the test beam. The variable $D$ from Eq.2 is the maximum deflection from the centre of the beam. The variable $\mathrm{m}$ in Eq. 3 is defined as the slope of the tangent to the initial straight-line portion of the load deflection curve.

By assuming certain key points, it is possible to determine the distribution of stress and strain in a composite in terms of its geometry distribution, the volume fraction of the fibers and elastic properties. The assumptions are as follows:

- The matrix and the fiber behave as elastic materials;

- The interface is infinitesimally thin;

- The fiber-matrix bond is perfect;

- The material close to the fiber as the same as the material is the bulk form;

- The fibers are arranged in a regular or repeating array. 
In a unidirectional aligned fiber reinforced polymer composite under tension $\mathrm{E}_{\mathrm{f}}$ and $\mathrm{E}_{\mathrm{m}}$ are the moduli of fiber and matrix respectively. $\mathrm{V}_{\mathrm{f}}$ is the fiber volume fraction. EII is the modulus when the fiber and matrix are parallel and experience the same strain, thus:

$$
E_{I I}=E_{f} V_{f}+E_{m}\left(1-V_{f}\right)
$$

EL is the modulus when the fiber and matrix are in series, thus experiences the same stress:

$$
E_{L}=\frac{E_{f} E_{m}}{E_{f}\left(1-V_{f}\right)+E_{m} V_{f}}
$$

The density of composites can be determined using Archimedes's principle:

$$
\rho_{c}=\frac{M_{a}}{\left(M_{a}-M_{w}\right)} \bullet \rho_{w}
$$

Where $\mathrm{Ma}$ is the mass of the sample in air, $\mathrm{M}_{\mathrm{w}}$ is the mass sample in water, $\rho_{\mathrm{w}}$ is the

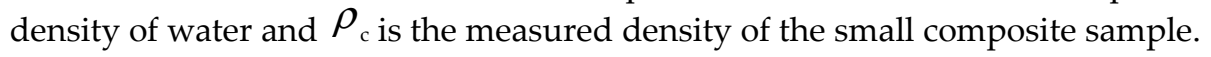

\section{Methods}

The experiment consists of characterizing three composites. The materials tested in the experiment included:
A: glass epoxy (green)
B: glass silicone (White)
C: glass polyester (red)

The experiment involved three tests, which were divided upon three groups of two students each. Each group was given one of the three samples to perform the tests. At the end of the experiment session, the final results were shared with each of the groups.

At one test station, each sample was cut in two standard specimen (ASTM D790) that were to be used for the flexural test apparatus as explained in the previous section. One sample was cut in the longitudinal direction. These samples are identified with double letters (AA, BB, CC). The second sample was cut in the transversal direction and identified with single letters (A, B, C). It is important to realize that this is not related to the actual direction of the fibers contained in the sample but only for sake of properly identifying the cut samples. The apparatus was properly measured as well as the width and thickness of the specimen. The specimen was then carefully placed into the apparatus. The flexural apparatus was set to a standard loading rate of $2 \mathrm{~mm} / \mathrm{min}$. Once the test has been carried out, a force vs. distance has been produced and printed. The test is repeated with the second specimen.

At a second test station, samples contained three small rectangular specimens used for calculating the mass in air and in water. This information is needed to calculate the density of the composite, which is then used to calculate the volume percent of each the fiber and the matrix. To measure the sample in air, the specimen is simply placed onto a precise balance. To measure the specimen in water, a beaker filled with water is placed onto the balance where a net is hanged in it. The specimen is placed into the net and the measurement recorded. 
The final station is to analyze the cross-section of the specimens. Both the longitudinal and transversal were analyzed. The purpose of the analysis is to observe the patterns of the fibers within the composite. The specimens used were already mounted and polished. The analysis took place using an optical microscope connected to a digital camera that feed the image to a computer program. The computer program was used to measure the diameter of the fibers and notice differences between the samples. The data collected through the observation will be used to help explain the failure mechanisms for both specimens of each sample in the flexural test. SEM images were also provided taken from another analysis session of the samples. It was not done during the experimental session due to a lack of time. The SEM images also used to help in the investigation of the failure mechanisms.

\section{Results}

Table 1. Sample Measurements for materials A, B and C for the transversal direction (single letters)

\begin{tabular}{|c|c||c|c||c|c|}
\hline \multicolumn{2}{|c||}{ Material A } & \multicolumn{2}{c||}{ Material B } & \multicolumn{2}{c|}{ Material C } \\
\hline \hline Thickness(mm) & Width $(\mathrm{mm})$ & Thickness $(\mathrm{mm})$ & Width $(\mathrm{mm})$ & Thickness $(\mathrm{mm})$ & Width(mm) \\
\hline 2.43 & 10.07 & 3.35 & 10.08 & 3.67 & 10.10 \\
\hline 2.44 & 10.57 & 3.24 & 10.49 & 3.70 & 9.76 \\
\hline 2.42 & 10.37 & 3.28 & 10.88 & 3.72 & 10.25 \\
\hline
\end{tabular}

Table 2. Sample Measurements for materials A, B and C for the longitudinal direction (double letters)

\begin{tabular}{|c|c||c|c||c|c|}
\hline \multicolumn{2}{|c||}{ Material A } & \multicolumn{2}{c||}{ Material B } & \multicolumn{2}{c|}{ Material C } \\
\hline \hline Thickness(mm) & Width(mm) & Thickness $(\mathrm{mm})$ & Width $(\mathrm{mm})$ & Thickness(mm) & Width(mm) \\
\hline 2.42 & 10.16 & 3.22 & 10.04 & 3.65 & 10.08 \\
\hline 2.43 & 10.05 & 3.23 & 10.01 & 3.68 & 10.42 \\
\hline 2.43 & 10.25 & 3.26 & 9.99 & 3.75 & 10.49 \\
\hline
\end{tabular}

Table 3. Mass measurements for all three samples from each material that will be used for composite density calculations

\begin{tabular}{|l|c|c||c|c||c|c|}
\cline { 2 - 6 } \multicolumn{1}{c|}{} & \multicolumn{2}{c|}{ Material A } & \multicolumn{2}{c|}{ Material B } & \multicolumn{2}{c|}{ Material C } \\
\cline { 2 - 7 } \multicolumn{1}{c|}{} & Air $(\mathrm{g})$ & Water $(\mathrm{g})$ & Air $(\mathrm{g})$ & Water $(\mathrm{g})$ & Air $(\mathrm{g})$ & Water $(\mathrm{g})$ \\
\hline $\mathbf{1}$ & 0.6748 & 0.3405 & 0.7686 & 0.3254 & 1.1376 & 0.5093 \\
\hline $\mathbf{2}$ & 0.6014 & 0.2967 & 1.0229 & 0.4493 & 1.3632 & 0.6140 \\
\hline $\mathbf{3}$ & 0.6492 & 0.3230 & 1.0735 & 0.4797 & 1.1663 & 0.5239 \\
\hline
\end{tabular}

Table 4: Composite density calculations using Archimedes' principle

\begin{tabular}{|c|c|c|c|}
\hline & Material A & Material B & Material C \\
\hline & Density $\left(\mathrm{g} / \mathrm{cm}^{\wedge} 3\right)$ & Density $\left(\mathrm{g} / \mathrm{cm}^{\wedge} 3\right)$ & Density $\left(\mathrm{g} / \mathrm{cm}^{\wedge} 3\right)$ \\
\hline 1 & 2.019 & 1.734 & 1.811 \\
\hline 2 & 1.974 & 1.783 & 1.820 \\
\hline 3 & 1.990 & 1.808 & 1.816 \\
\hline
\end{tabular}


Table 5. Flexural stress calculations for both composite directions

\begin{tabular}{|l|c|c||c|c||c|c|}
\cline { 2 - 6 } \multicolumn{1}{c|}{} & \multicolumn{2}{c||}{ Material A } & \multicolumn{2}{c||}{ Material B } & \multicolumn{2}{c|}{ Material C } \\
\cline { 2 - 6 } \multicolumn{1}{c|}{} & \multicolumn{2}{c||}{ Flexural Stress (MPa) } & Flexural Stress (MPa) & \multicolumn{2}{c|}{ Flexural Stress (MPa) } \\
\cline { 2 - 6 } \multicolumn{1}{c|}{} & Trans. & Long. & Trans. & Long. & Trans. & Long. \\
\hline $\mathbf{1}$ & 430.9 & 536.3 & 128.4 & 115.9 & 132.3 & 144.8 \\
\hline $\mathbf{2}$ & 407.2 & 537.7 & 131.9 & 115.5 & 134.7 & 137.8 \\
\hline $\mathbf{3}$ & 421.9 & 527.2 & 124.0 & 113.6 & 126.9 & 131.8 \\
\hline
\end{tabular}

Table 6. Elastic modulus calculations for both composite directions

\begin{tabular}{|l|c|c||c|c||c|c|}
\cline { 2 - 6 } \multicolumn{1}{c|}{} & \multicolumn{2}{c||}{ Material A } & \multicolumn{2}{c||}{ Material B } & \multicolumn{2}{c|}{ Material C } \\
\cline { 2 - 7 } \multicolumn{1}{c|}{} & \multicolumn{2}{c||}{ Elastic Modulus (GPa) } & \multicolumn{2}{c||}{ Elastic Modulus (GPa) } & \multicolumn{2}{c|}{ Elastic Modulus (GPa) } \\
\cline { 2 - 7 } & Trans. & Long. & Trans. & Long. & Trans. & Long. \\
\hline $\mathbf{1}$ & 16.1 & 18.3 & 2.6 & 2.2 & 3.4 & 1.8 \\
\hline $\mathbf{2}$ & 15.1 & 18.2 & 2.8 & 2.2 & 3.5 & 1.7 \\
\hline $\mathbf{3}$ & 15.8 & 17.9 & 2.6 & 2.1 & 3.3 & 1.5 \\
\hline
\end{tabular}

Table 7. Mean and Standard Deviation of composites in both directions

\begin{tabular}{|c|c|c|c|c|c|c|c|c|c|c|c|c|}
\hline & \multicolumn{4}{|c|}{ Material A } & \multicolumn{4}{|c|}{ Material B } & \multicolumn{4}{|c|}{ Material C } \\
\hline & \multicolumn{2}{|c|}{$\sigma(\mathrm{MPa})$} & \multicolumn{2}{|c|}{ E (GPa) } & \multicolumn{2}{|c|}{$\sigma(\mathrm{MPa})$} & \multicolumn{2}{|c|}{$\mathrm{E}(\mathrm{GPa})$} & \multicolumn{2}{|c|}{$\sigma(\mathrm{MPa})$} & \multicolumn{2}{|c|}{$\mathrm{E}(\mathrm{GPa})$} \\
\hline & Trans. & Long. & Trans. & Long. & Trans. & Long. & Trans. & Long. & Trans. & Long. & Trans. & Long. \\
\hline Mean & 420 & 533.7 & 15.7 & 18.1 & 128.1 & 115.0 & 2.7 & 2.2 & 131.3 & 138.1 & 3.4 & 1.7 \\
\hline S.D & 12.3 & 5.1 & 0.4 & 0.7 & 4.3 & 0.3 & 0.2 & 0.1 & 4.4 & 3.8 & 0.2 & 0.2 \\
\hline
\end{tabular}

Table 8. Volume fraction, mass fraction and fiber diameter for all composites

\begin{tabular}{|c|c|c||c|c|c||c|c|c|}
\hline \multicolumn{3}{|c||}{ Material A } & \multicolumn{3}{c||}{ Material B } & \multicolumn{3}{c|}{ Material C } \\
\hline \hline $\mathrm{V}_{\mathrm{f}}$ & $\mathrm{m}_{\mathrm{f}}$ & $\mathrm{d}_{\mathrm{f}}(\mu m)$ & $\mathrm{V}_{\mathrm{f}}$ & $\mathrm{m}_{\mathrm{f}}$ & $\mathrm{d}_{\mathrm{f}}(\mu m)$ & $\mathrm{V}_{\mathrm{f}}$ & $\mathrm{m}_{\mathrm{f}}$ & $\mathrm{d}_{\mathrm{f}}(\mu m)$ \\
\hline 0.38 & 0.79 & 12 & 0.47 & 0.71 & 8 & 0.45 & 0.70 & 18 \\
\hline
\end{tabular}

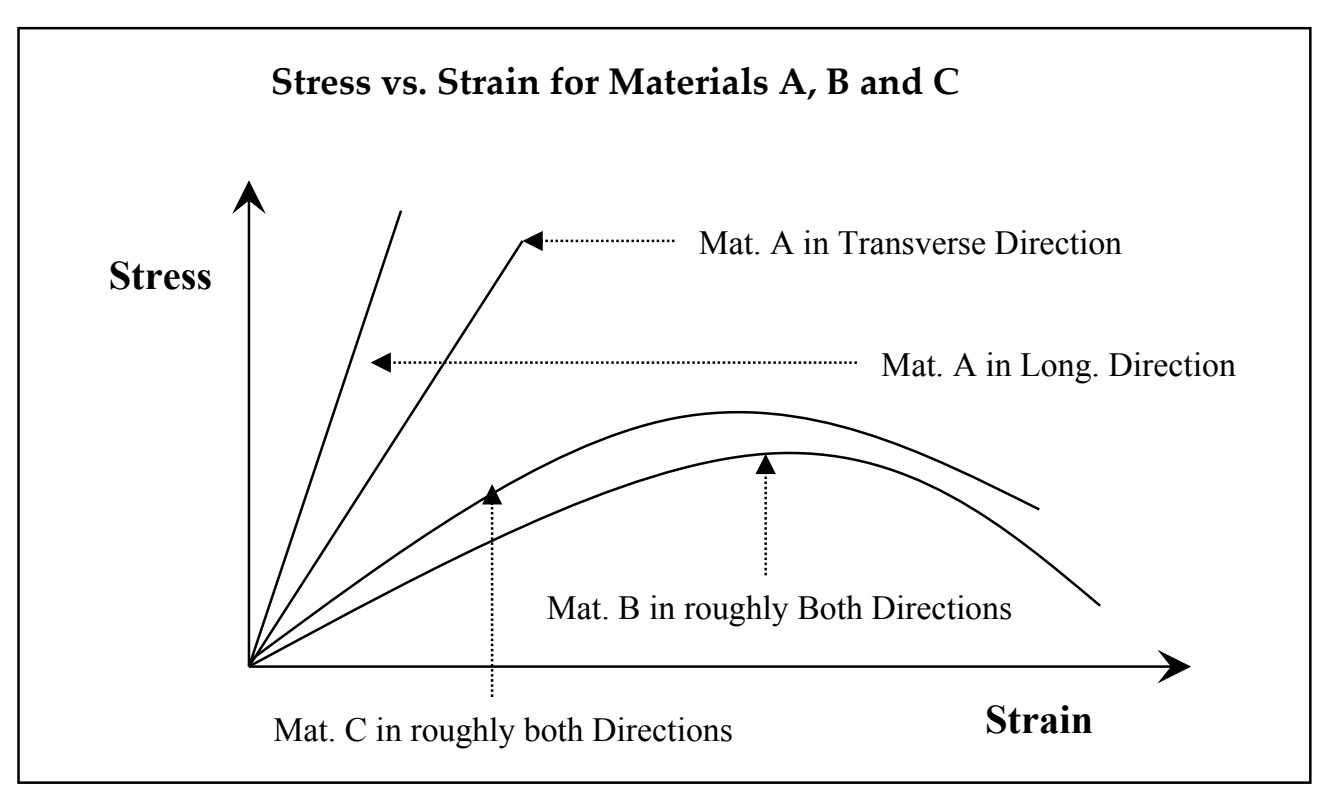

Figure 2. Stress-Strain diagram Materials A, B and C 
4.1 Sample calculations for Material A:

Density of composite for sample A1 using Archimedes's principle:

$$
\begin{aligned}
\left(\rho_{c}\right)_{A 1} & =\frac{M_{a}}{\left(M_{a}-M_{w}\right)} \bullet \rho_{w} \\
\left(\rho_{c}\right)_{A 1} & =\left(\frac{0.6748 g}{0.6748 g-0.3405 g}\right) \bullet 1.00 \mathrm{~g} / \mathrm{cm}^{3} \\
\left(\rho_{c}\right)_{A 1} & =2.019 \mathrm{~g} / \mathrm{cm}^{3}
\end{aligned}
$$

Flexural strength of composite A (transversal direction):

$$
\begin{aligned}
\left(\sigma_{f}\right)_{A 1} & =\frac{3 F L}{2 b d^{2}} \\
\left(\sigma_{f}\right)_{A 1} & =\frac{(3)(269 N)(0.0635 m)}{(2)(0.00243 m)^{2}(0.01007 m)} \\
\left(\sigma_{f}\right)_{A 1} & =430.9 M P a
\end{aligned}
$$

Note:

The 269N force was found when the sample failed.

Elastic modulus of composite A (transversal direction):

$$
\begin{aligned}
(E)_{A 1} & =\frac{F L^{3}}{4 b d^{3} D} \\
(E)_{A 1} & =\frac{(0.0635 m)^{3}(269 N)}{(4)(0.01007 m)(0.00243 m)^{3}(0.007425 m)} \\
(E)_{A 1} & =16.05 G P a
\end{aligned}
$$

Where:
$\mathrm{D}$ is the maximum vertical displacement of the sample at the point of failure. This information was given on the data log sheet.

\section{Note :}

The same calculations are repeated for the $A A$ samples (Flexural strength and Elastic modulus), which is the longitudinal direction.

The mean and standard deviation of the three composite used for composite density calculations (A1, A2, A3):

$$
\begin{aligned}
& \bar{x}=\frac{\sum_{i=1}^{N} x_{i}}{N} \\
& \bar{x}=\frac{2.019+1.974+1.990}{3} \\
& \bar{x}=1.994 \mathrm{~g} / \mathrm{cm}^{3}
\end{aligned}
$$

$$
\begin{aligned}
& \sigma=\sqrt{\frac{1}{N} \sum_{i=1}^{N}\left(x_{i}-\bar{x}\right)^{2}} \\
& \sigma=\sqrt{\frac{1}{3}(6.25+4+1.6)} \\
& \sigma=12.3
\end{aligned}
$$

Note:

The same calculations are done for calculating the mean and standard deviation for the flexural strength and modulus of elasticity.

The volume fraction of material A using the mean composite density: 
$\rho_{c}=\frac{M_{f}}{V}+\frac{M_{m}}{V}$

$\rho_{c}=\frac{v_{f} \rho_{f}}{V}+\frac{v_{m} \rho_{m}}{V}$

$* \frac{v_{f}}{V}=V_{f}$

$\rho_{c}=V_{f} \rho_{f}+V_{m} \rho_{m}$

$\rho_{c}=V_{f} \rho_{f}+\left(1-V_{f}\right) \rho_{m}=V_{f}\left(\rho_{f}-\rho_{m}\right)+\rho_{m}$

$1.994=V_{f}(2.54-1.1)=1.1$

$V_{f}=0.62$

$V_{m}=0.38$

Note:

The elastic modulus of the fiber and matrix alone was not given, a mathematical expression was derived to determine the volume fraction of the fiber using the constituents densities.
The mass fraction of the fiber in composite A:

$$
\begin{aligned}
& M_{c}=M_{m}+M_{f} \\
& M_{c}=\rho_{m} V_{m}+M_{f} \\
& 0.6748=(1.10)(0.129)+M_{f} \\
& M_{f}=0.533 g \\
& m_{f}=\frac{M_{f}}{M_{\text {total }}}=\frac{0.533}{0.6748}=0.79
\end{aligned}
$$

Note:

These calculations are repeated for materials $B$ and $C$ as well. 


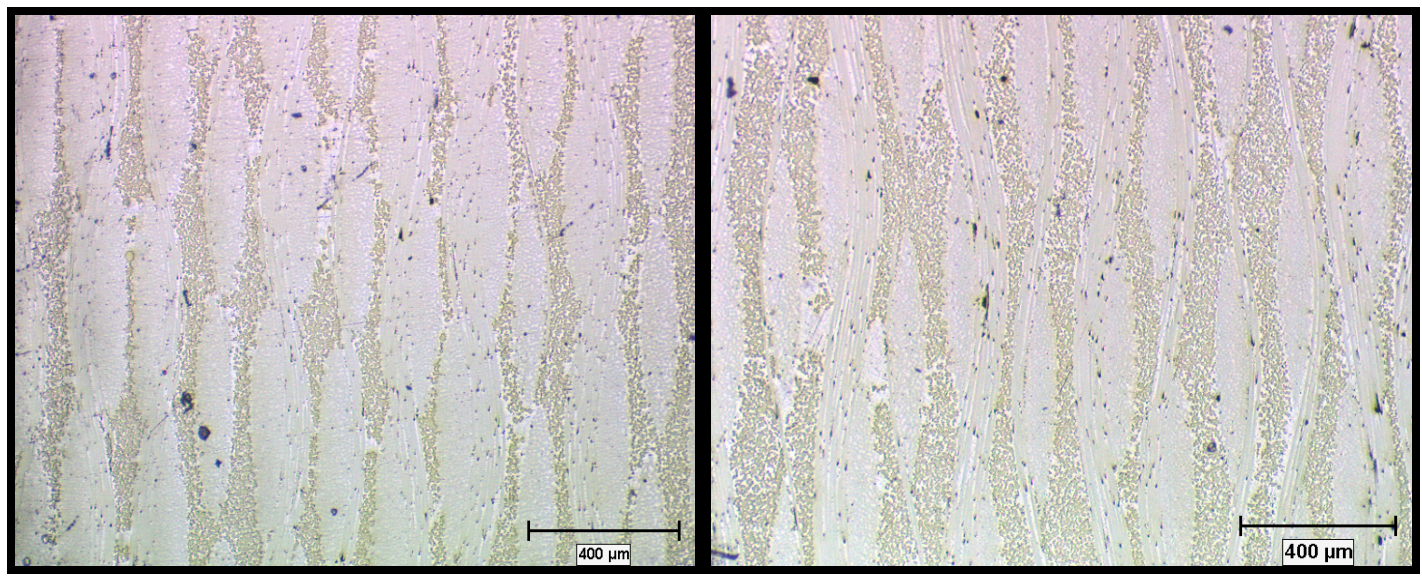

Figure 3. Material A at 50x magnification. Right image is the longitudinal direction and the left image the transverse direction
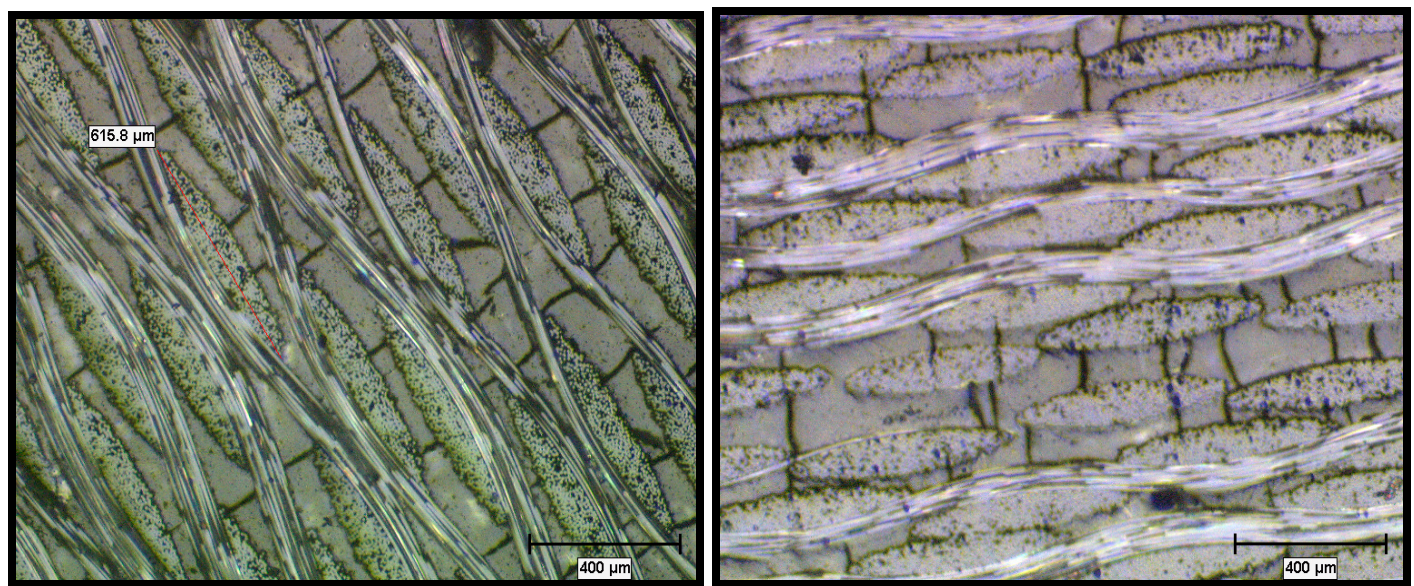

Figure 4. Material B at 50x magnification. Right image is the longitudinal direction and the left image the transverse direction

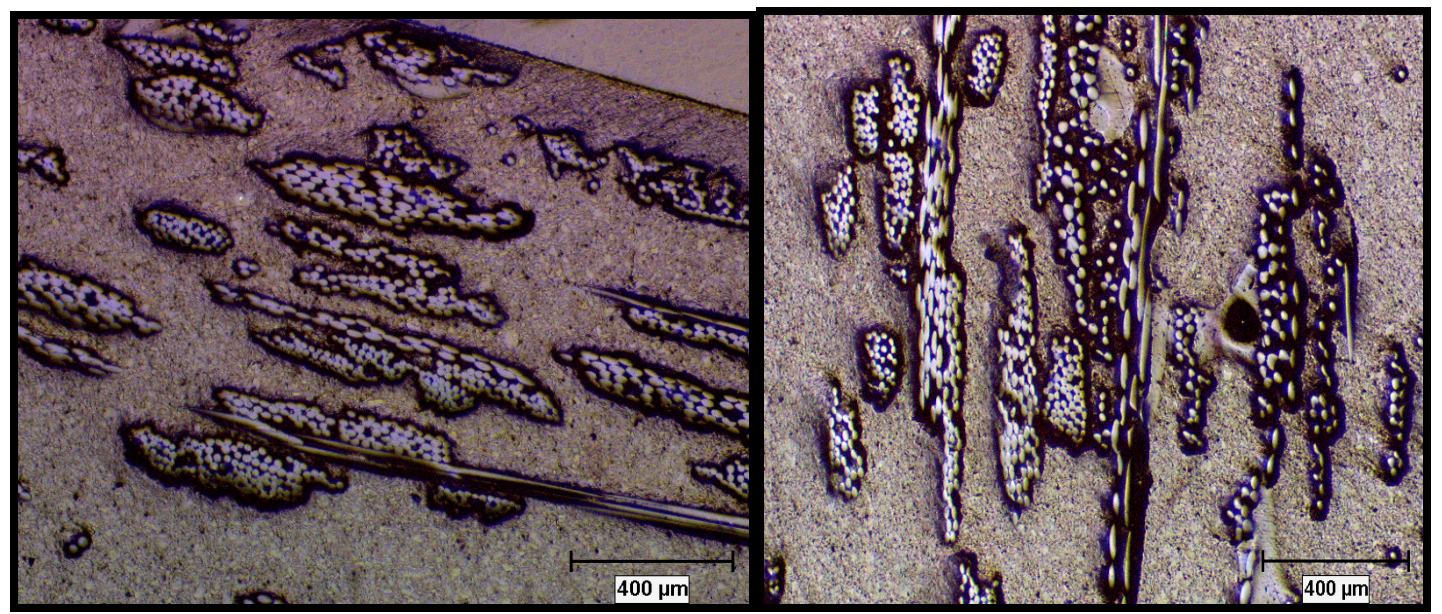

Figure 5. Material $\mathrm{C}$ at 50x magnification. Right image is the longitudinal direction and the left image the transverse direction 


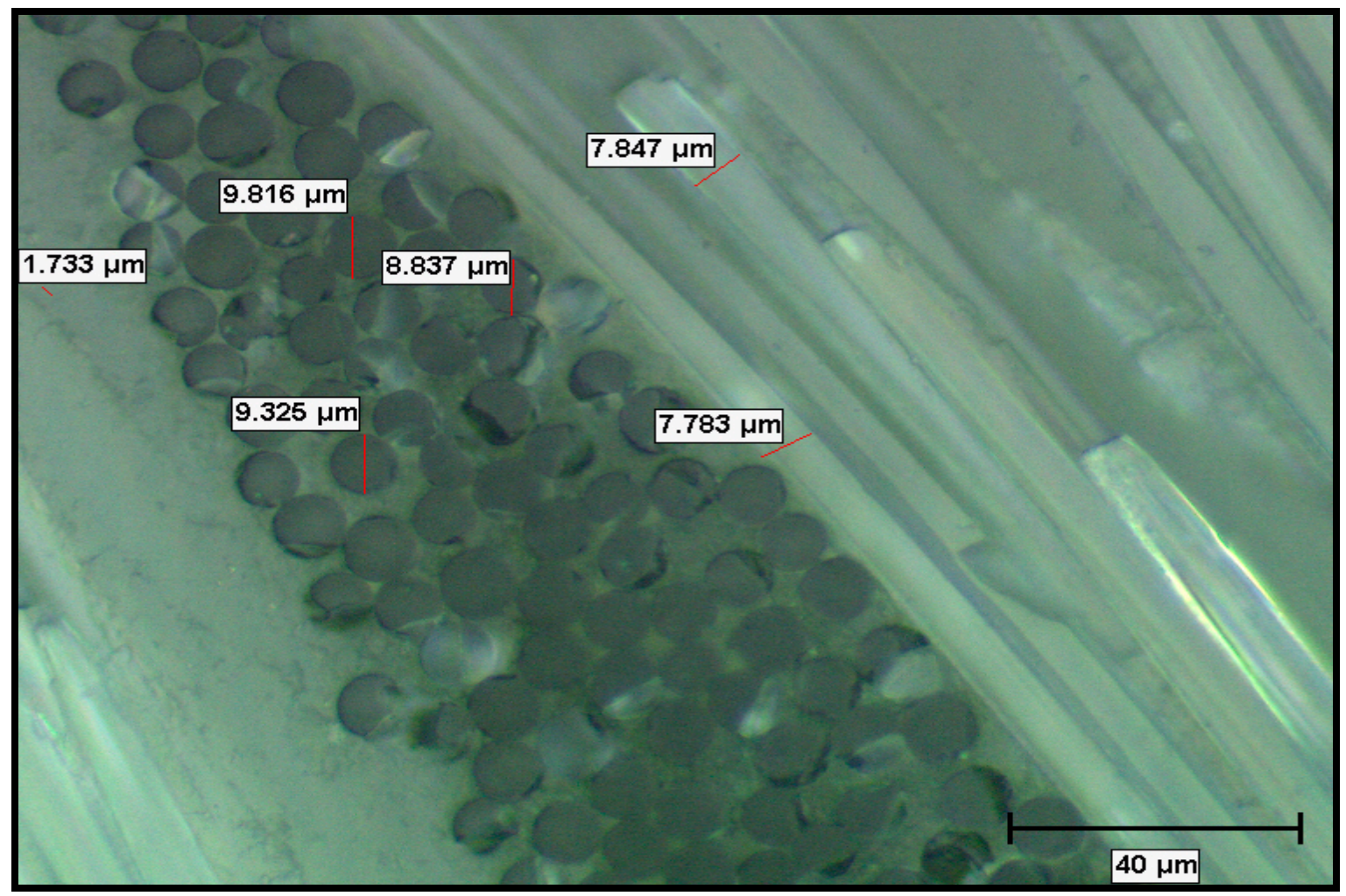

Figure 6. Material B at 500x magnifications with clear representation of the fiberglass fibers

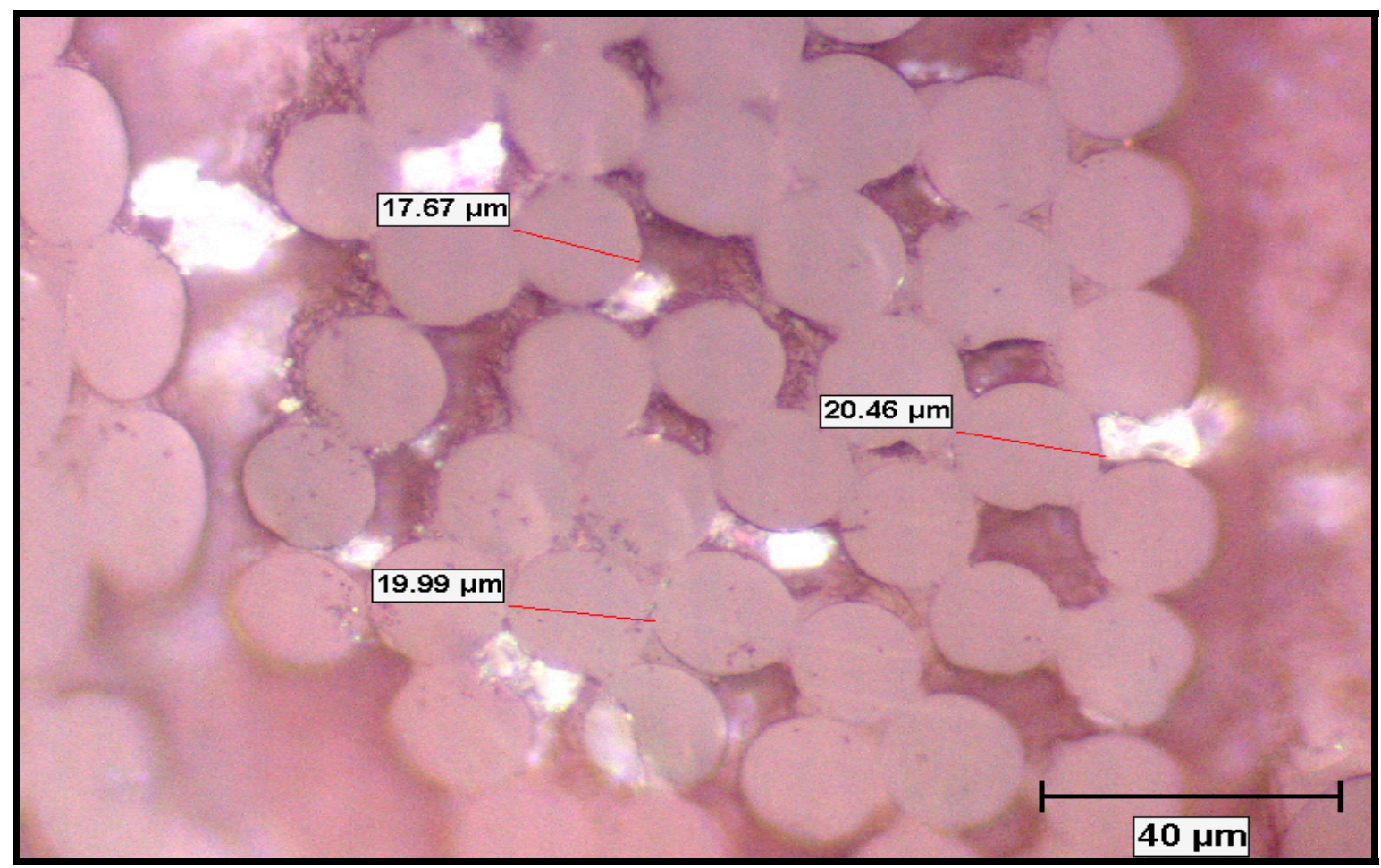

Figure 7. Material C at 500x magnifications with clear representation of the fiberglass fibers 


\section{Discussion}

Material A showed the most evidence of isotropy and is the reason why the flexural stress varied from $420 \mathrm{MPa}$ in the transverse direction to roughly $530 \mathrm{MPa}$ in the longitudinal direction. From observing the SEM figures for Material A, It was found from observing the SEM and optical images that the material wasn't completely unidirectional and the fibers are somewhat weaved. The difference is that the longitudinal direction (AA) had much more of a volume fraction occupied from fibers and therefore made the material stronger that that particular direction. There is more fibers in the longitudinal direction. Epoxy is considered a ductile material and from the flexural testing, the fracture observed was very brittle, suggesting the composite contained a higher mass fraction of fiber. The fibers are actually lined longitudinally in the AA sample since it was able to withstand more load. From the crack observation, it was clear that there was more plastic deformation from the AA sample. This was seen by a larger change in color on the surface. Since there is more fiber in this direction, the composite is much stronger and the matrix was under a larger load, causing the matrix to enter it's plastic zone more intensely. The composite takes on the property of the constituents and since the mass percent of the fiber was found to be $79 \%$, it becomes obvious why this composite is so brittle but strong. The fiber diameter was found to be roughly 12 microns.

Material B showed very little variations to it's flexural stress in both direction. It would be said that this material is somewhat anisotropic from both the flexural test results. From the optical-SEM images, it was found that the transverse direction contained a larger volume fraction of fibers along the longitudinal direction. The flexural stress in this direction was also slightly higher, confirming the observation. From primarily observing the fractured specimen, it didn't crack such as Material A. Material A failed completely vertically as such it was cut intentionally. Material B degraded in layers in both samples. When observing the SEM specimen specifically, it became clear that the fiberglass is very heavily weaved and would cause this effect when it would fail. The strength of the material is significant weaker than that of Material A. The flexural stress was found to be $128 \mathrm{MPa}$. The volume percent of fiberglass was found to be $47 \%$, which is $9 \%$ more than material A. The reason why this material was found to be weaker is because of the woven pattern of the fibers. The way the fibers are oriented has equated the strength in both direction whereas material A has higher strength in one particular direction and lacks strength in the other.

Material $C$ is considered completely anisotropic due to the random orientation of the fiberglass. It was also found that the fiberglass is also not as long as the other two samples. From Fig. 5 it is notice that certain fibers are shaped as ellipses. This is not the actual shape of the fiber but the angle of the image. Since the fibers are orientated randomly, when the sample is cut, certain fiber are not cut exactly vertically and gives this illusion. The diameter of the fibers where found to be the biggest at roughly 18 microns. It was most likely manufactured this way to give more structural stability to the matrix since the fibers are short and randomly placed. The flexural stress was found to be roughly $135 \mathrm{MPa}$ when the mean is taken from both the transverse and longitudinal direction. The percent volume of fiberglass was found to be $45 \%$. This is roughly the same as Material B and there flexural stress almost match as well. This was a surprising discovery considering the two composite are made from two very different reinforcement technique. This can be explained from the polyester matrix of material C. Polyester is a slightly stronger material and was able to withstand more load. If material $C$ had been woven fibers, the fibers would have resisted more load compared to material $\mathrm{B}$. Woven fibers are able to maintain better the matrix 
layers more ordered. The fractures of material $\mathrm{C}$ where completely random and this was expected after observing the optical images. Since the fibers where randomly orientated, the polyester matrix dislocated from the fibers without snapping the fibers. The fractured sample was still in one single piece since the fibers were still holding the fractured matrix together.

The flexural stress calculated match those of the referred theoretical values found in the data sheet with an error not exceeding $7 \%$. When applying a composite to an application, it is crucial to determine the right fiber reinforcement. A component that will experience forces in multiple directions, the fiber composite should have random or woven fiber orientation. A specific component that will experience a certain large load in one particular direction, fibers should be longitudinally placed relative to the matrix. Woven fiber orientation is best suited for thick materials that help maintain the structure of the composite, especially for a more ductile matrix. Composite are extremely helpful materials for certain applications mostly due to there light weight. The fact that the composite mechanical properties reflect the properties of there constituents is a great advantage. The material can hold dual properties such as ductility and strength depending on the volume fraction of each phase. When comparing certain reinforced composites such as carbon fiber, they tend to be much stronger than metals when taking account there weight ratio. Carbon fiber is a superior stiff, strong and extremely light material apposed to steel.

\section{Conclusions}

1) Unidirectional fiber orientation is significantly stronger in only one particular direction as apposed to its crosswise direction.

2) Random orientated fibers resist a lower overall load as compared to unidirectional fibers but the load it can withstand are constant in every direction.

3) Woven orientated fibers can still offer anisotropy properties and further add stiffness to the soft matrix. Woven fibers are more superior under tension forces as compared to compression loads.

4) Composites are very good in holding multiple mechanical properties that is proportional to the volume fraction of there constituents.

5) Material A behaves very brittle on the stress-strain graph due to the fracture surface, which was a very clean cut and snapping of the fibers; Materials B and C behaves more as a ductile material on the stress-strain graph because the fibers never snapped upon fracture. The matrix failed.

6) Certain composites such as carbon fibers are stronger than steels when comparing them against there weights.

7) Composites are very hard to shape in complex shapes, making them very expensive and time consuming to produce.

\section{Conflicts of Interest}

The authors declare no conflict of interest.

The funding sponsors had no role in the design of the study; in the collection, analyses, or interpretation of data; in the writing of the manuscript, and in the decision to publish the results. 


\section{References}

1. Callister W D. Materials Science and Engineering An Introduction, 5th Edition, john Wily \& Sons, Inc., New York, USA, 2000; pp. 124-151.

2. Hristozov D, Wroblewski L, Sadeghian P. Long-term tensile properties of natural fiberreinforced polymer composites: Comparison of flax and glass fibers. Composites Part B Engineering, 2016; 95: pp. 82-95.

3. Sims G D, Broughton W R. In: Kelly A, Zweben C, editors. Glass fiber reinforced plasticsproperties. Comprehensive composite materials, vol. 2. 1st ed. London: Elsevier; 2000. pp. 165.

4. Chilali A, Zouari W, Assararm M, Rezak A. Analysis of the mechanical behavior of flax and glass fabrics-reinforced thermoplastic and thermo-set resins. Journal of Reinforced Plastics and Composites, 2016; 35(16): pp. 1217-1232.

5. Hinrichsen G, Mohanty A, Misra M. Bio-fibers, biodegradable polymers and biocomposites: an overview. Macromolecular Materials and Engineering, 2000; 276/277: pp. 1-24.

6. Prambauer M, Paulik C, Burgstaller C. Evaluation of the interfacial properties of polypropylene composite laminates, reinforced with paper sheets. Composites Part A Applied Science \& Manufacture, 2016; 88: pp. 59-66.

7. Folkes M. In: Belvis M, editor. Short fiber reinforced thermo-plastics. Herts: John Wiley \& Sons Ltd.; 1985. pp.151.

8. Prambauer M, Paulik C, Burgstaller C. Mechanical Properties of Structural PaperPolypropylene Composite Laminates. Materials Science Forum, 2015; 54(11): pp.91-93.

9. Racz I, Hargitai H. Influence of water on properties of cellulosic fiber reinforced polypropylene composites. International Journal of Polymeric Materials, 2000; 47: pp. 667-674.

10. Jang J, Lee N-J. The effect of fiber-content gradient on the mechanical properties of glassfiber-mat/polypropylene composites. Composites Science and Technology, 2000; 60: pp. 209-217.

11. Mohanty AK, Rout J, Misra M, Tripalty SS, Nayak SK. Novel Eco-Friendly Biodegradable Coir-Polyester Amide Bio-composites: Fabrication and Properties Evaluation. Polymer Composites, 2001; 22(6): pp. 770-778.

12. Wambua P, Ivens J, Verpoest I. Natural fibers: Can they replace glass in fiber reinforced plastics? Composites Science and Technology, 2003; 63(9): pp. 1259-1264.

(C) 2016 by the authors; licensee Preprints, Basel, Switzerland. This article is an open access article distributed under the terms and conditions of the Creative Commons by Attribution (CC-BY) license (http://creativecommons.org/licenses/by/4.0/). 